\title{
MORPHOLOGICAL AND HISTOLOGICAL IDENTIFICATION OF "FASCIOLA GIGANTICA" RECOVERED FROM LIVER OF INFECTED BUFFALOES
}

Pandya, S. S. ${ }^{*}$, Hasnani, J. J. ${ }^{2}$ and Patel, P. V. ${ }^{3}$

*1,2,3 Department of Veterinary Parasitology, College of Veterinary Science and Animal Husbandry, AAU, Anand, Gujarat, INDIA.

*Correspondence Author: pandyasuchit@gmail.com

\section{Abstract:}

This study was undertaken to identify Fasciola giganticai on the basis of its morphology and histology to be the common cause of fasciolosis in infected buffaloes.

Material \& Method: Adult liver flukes were recovered from the liver of naturally infected buffaloes slaughtered in various abattoirs in Gujarat. Some adult flukes were flattened, put between two slides, pressed and stained in Borax carmine, and some flukes were sectioned in the median sagittal plane and histological slides of the flukes were prepared for detailed morphological and histological studies.

Result: Microscopic pictures of the parasite used in identification defines the similarity in the morphology and histology of the $F$. gigantica on the basis of morphology of flukes; anterior sucker, posterior sucker (acetabulum), pharynx, uterus, ovary and type of epithelium.

Conclusion: It can be concluded that the most common species found in buffaloes infected with Fasciola gigantica on the basis of its histo-morphological appearance in Gujarat.

Keywords:

Fasciolosis, liver fluke, buffaloes, abattoirs, morphology, histology.

Cite This Article: Pandya, S. S., Hasnani, J. J. and Patel, P. V., "Morphological and Histological Identification of "Fasciola Gigantica" Recovered from Liver of Infected Buffaloes." International Journal of Research - Granthaalayah, Vol. 3, No. 3(2015): 25-31.

\section{INTRODUCTION}

Fasciolosis is one of the most important diseases of buffaloes in humid tropical regions of the world. Milk production is a livestock enterprise in which small-scale farmers can successfully engage in order to improve their livelihoods and this milk production is decreased by infection of Fasciola spp. parasite in buffaloes (Gupta et al., 2012). Fasciolosis in buffaloes is asymptomatic, subclinical and/or chronic form of the disease, adversely affecting their reproductive cycle, weight gain, food conversion efficiency and productivity. The frequency of outbreaks increases between October and May, but sporadic outbreaks continue throughout the year (Agrawal, 1998). Acute form of Fasciolosis caused by migratory immature flukes in the liver parenchyma is rare in cattle and buffaloes, and is difficult to diagnose as no eggs are detected in faeces. Chronic Fasciolosis mostly occurred in large ruminants viz. cattle and buffaloes (Chandra et al., 2011). Cases of acute Fasciolosis in buffaloes are rarely reported from India except Banerjee et 


\section{INTERNATIONAL JOURNAL of RESEARCH -GRANTHAALAYAH \\ A knowledge Repository}

Science

al., 2001 who has reported one such outbreak in Nainital district of Uttarakhand. The main purpose of this study is to identify the species of liver fluke causing Fasciolosis in buffaloes.

\section{MATERIALS AND METHODS}

\subsection{COLLECTION OF PARASITES}

The liver of buffaloes was inspected for the presence of liver flukes during slaughter at various abattoir places in Gujarat. Adult flukes were recovered from the parenchyma of liver of naturally infected buffaloes and then washed 3-4 times with phosphate buffer saline (PBS). After washing, samples were preserved in $10 \%$ buffered formalin until being processed for morphological and histological studies. The samples were carefully labelled with proper details.

\subsection{MORPHOLOGICAL IDENTIFICATION}

Liver flukes were primarily examined and identified under stereoscopic microscope under low power for outer morphological characteristics viz, its shape, anterior sucker, posterior sucker (acetabulum), terminal genitalium and epithelium, following the standard guidelines given by Urquhart et al., 1996. Parasites were processed for whole mounting and stained by Borax carmine according to procedure given by Singh and Srivastava, 1977. Recovered adult flukes from liver of infected buffaloes were washed in water, flattened between two glass slides and fixed in Bouin's fluid at room temperature for 24 hours. After that, these flukes were stained for 24 hours in $0.5 \%$ Borax carmine and subsequently de-stained in $1 \%$ hydrochloric acid until the pink color was observed. The acid was thoroughly washed out from all specimens with water. Thereafter, the specimens were washed with tap water and subsequently dehydrated through 50$100 \%$ alcohol for 1 hour each, and cleared by xylene for 30 minutes. The cleared specimens were mounted using DPX and covered with cover slip. The mounted slides were allowed to air dry and observed under the light microscope.

\subsection{HISTOLOGICAL IDENTIFICATION}

Formalin preserved thirty parasites were processed by paraffin embedding method and stained by H \& E stain as per Luna, 1968. Ten longitudinal and median sagittal sections, each 6-10 $\mu$ thick were cut by a Leica RM2125 microtome. The prepared sections were stained with Hematoxylin \& Eosin stain and were examined by microscopy and microphotography in order to identify oral and ventral suckers, testes and ovary.

\section{RESULTS AND DISCUSSIONS}

The histo-morphological examination of $F$. gigantica in the present study was done on the basis of morphology of flukes; anterior sucker, posterior sucker (acetabulum), pharynx, uterus, ovary, type of epithelium. 


\section{INTERNATIONAL JOURNAL of RESEARCH -GRANTHAALAYAH

\subsection{MORPHOLOGICAL IDENTIFICATION}

In the present study, it was observed that $F$. gigantica had a less prominent shoulder and having 25-35 mm body length. Cuticle was thick, smooth except at genital pore and anterior extremity which was covered with numerous prominent papillae. Both anterior and posterior suckers had thick rims covered with transverse folds (Fig. 1).

\subsection{HISTOLOGICAL IDENTIFICATION}

The ventral sucker is situated at the level of the shoulder and tegument is armed with sharp spines. Pharynx is situated just after the oral sucker. Uterus is situated posterior to the ventral sucker and anterior to the testes and ovary is situated right of the middle of the fluke (Fig. 2 and 3). Mehlis gland was close to ovary (Fig. 2). The testes are much branched and filling the median plane of the fluke (Fig. 4). The digestive tract of the fluke covered with two type of epithelium, tegumental epithelium and caecal type of epithelium. The major portion of the digestive tract is lined by caecal type of the epithelium (Fig. 5).

Similar findings were documented by Meemon et al. (2010) noted that the digestive tract of Fasciola gigantica is composed of the oral sucker, buccal tube, pharynx, oesophagus, and caecum. The tegumental type epithelium lines the first four parts of the digestive tract while the caecal type epithelium lines the remaining parts from the caecal bifurcation. Kuchai et al. (2013) who reported Fasciola gigantica more cylindrical, large, narrow, grayish-brown in colour and even more leaflike in shape, conical head process, a direct continuation of body, resulting in almost total absence of shoulders, lateral body margins are parallel, posterior end of the body absolutely rounded or bluntly constricted, large pharynx, which is completely in line with the our study. 


\section{INTERNATIONAL JOURNAL of RESEARCH -GRANTHAALAYAH}

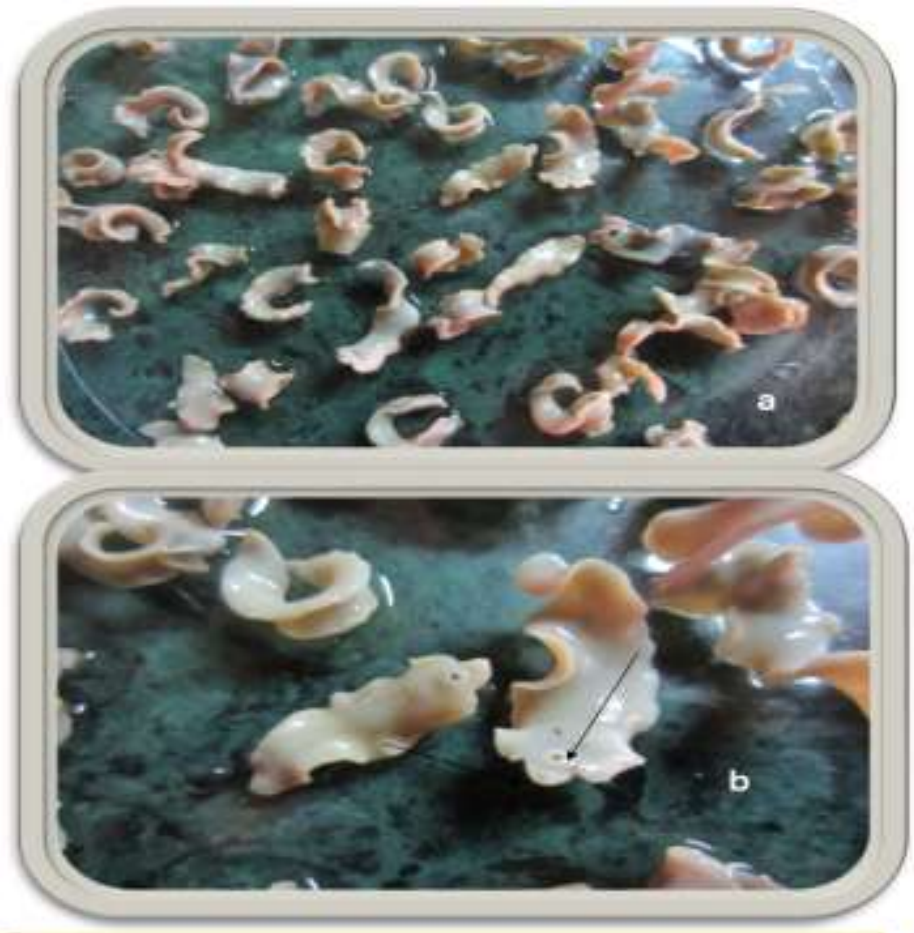

Figure 1, a Oross specimen of Frociola grgandsca, b, Oral mad ventral rucker of Fasciola sleawbed

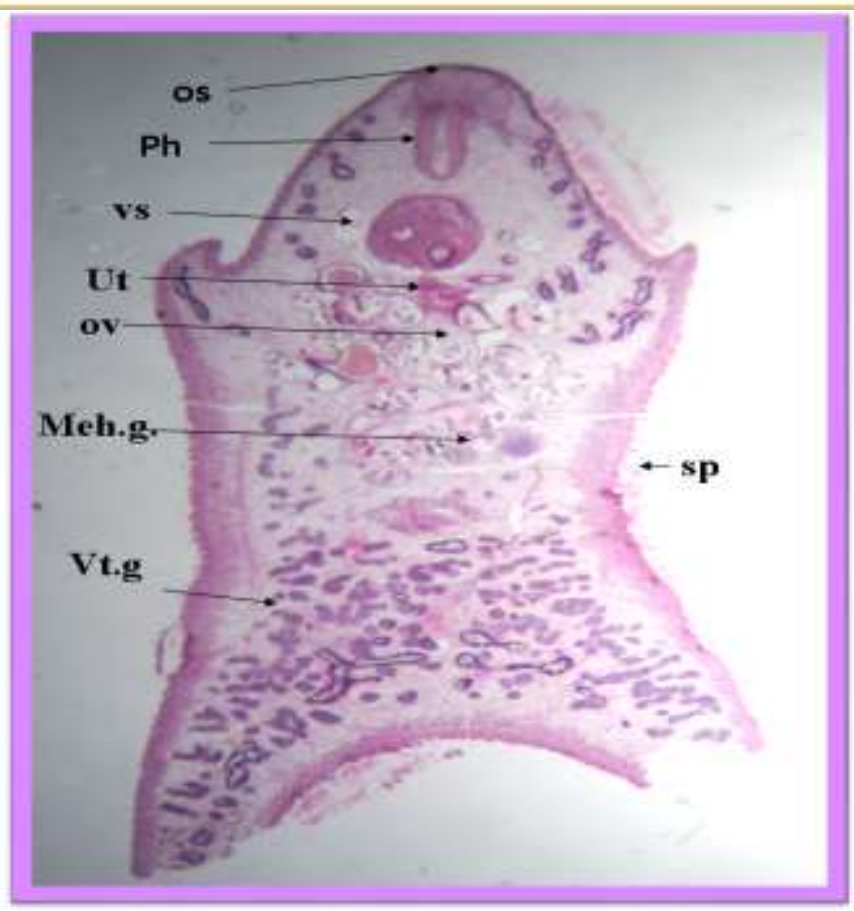

Figure 2. Mierescup ie pietures showing Mouth parts of Fasedola grgentied, af at macker (os), ventral sucker (ve), pharynar (Ph), utenis (ut), ovary (ov), tegument armed

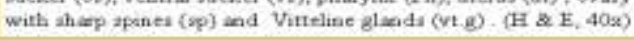




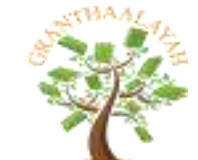

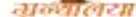
Science

\section{INTERNATIONAL JOURNAL of RESEARCH -GRANTHAALAYAH}

A knowledge Repository

口䋨回

74

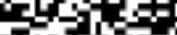

insty

回都员
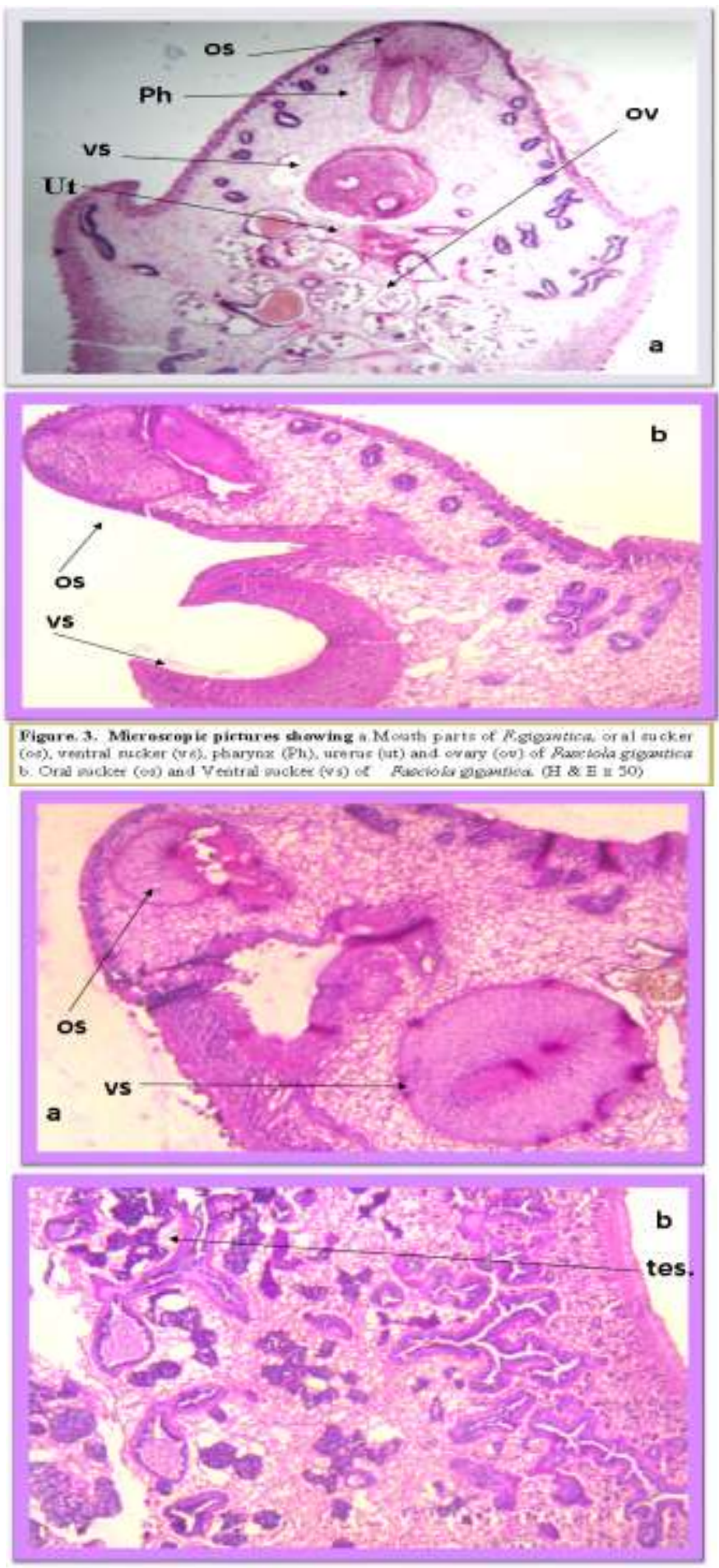

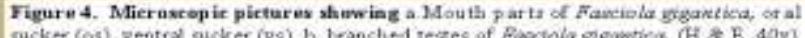

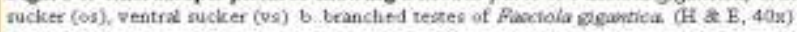




\section{INTERNATIONAL JOURNAL of RESEARCH -GRANTHAALAYAH \\ A knowledge Repository}

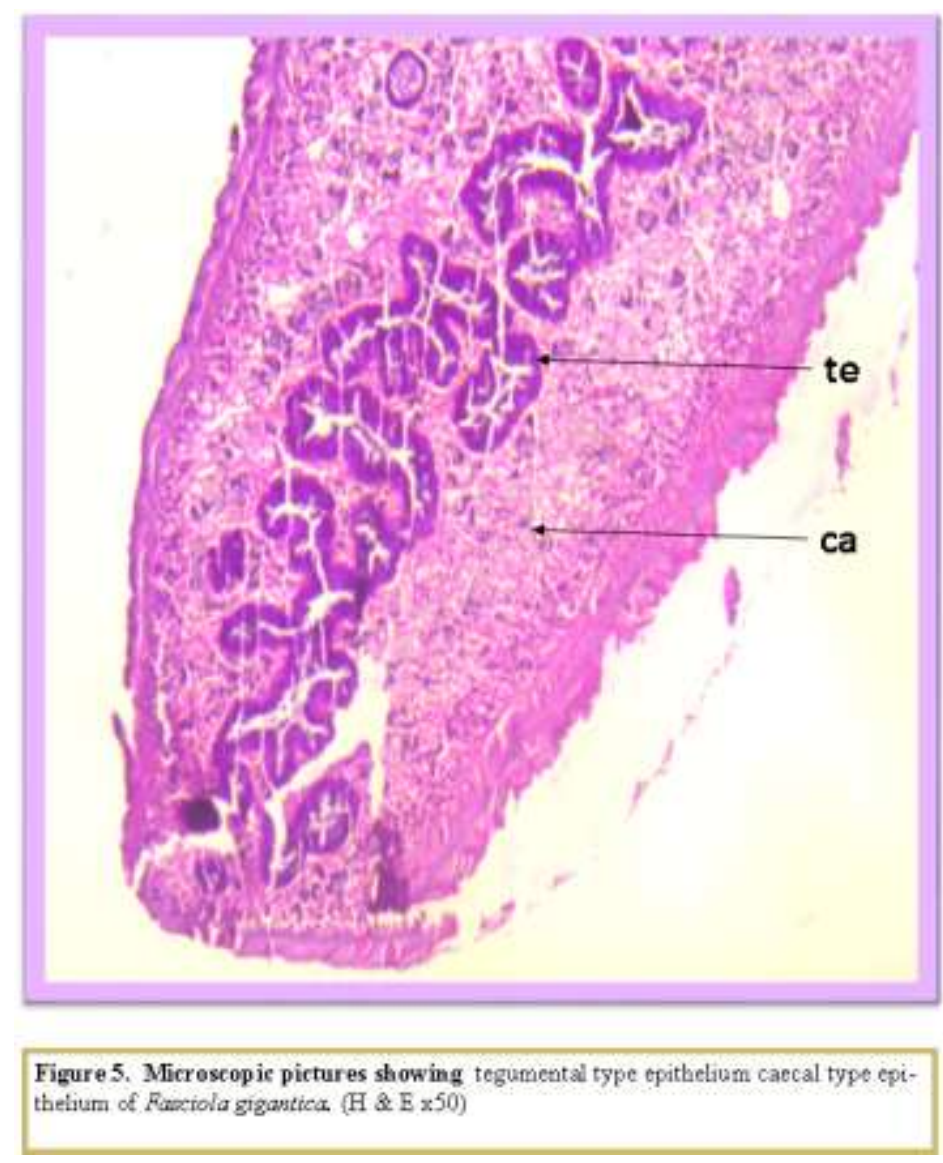

\section{CONCLUSION}

The testes are much branched and filling the median plane of the fluke (Plate 7). Uterus is situated posterior to the ventral sucker and anterior to the testes and ovary is situated right of the middle of the fluke. The digestive tract of the fluke covered with two type of epithelium, tegumental epithelium and caecal type of epithelium. The major portion of the digestive tract is line by caecal type of the epithelium. Mehlis gland was close to ovary.

\section{ACKNOWLEDGEMENT}

This study was funded by College of Veterinary Science and Animal Husbandry, Anand Agricultural University, Anand, Gujarat, India. The authors are thankful to all staff of Department of Veterinary Parasitology, College of Veterinary Science and Animal Husbandry, Anand Agricultural University, Anand, Gujarat, India for their help. The authors acknowledge the help rendered by the Department of Veterinary Pathology, AAU, Anand, Gujarat for providing facility for histology. 


\section{INTERNATIONAL JOURNAL of RESEARCH -GRANTHAALAYAH \\ A knowledge Repository}

Science

\section{REFERENCES}

[1] Gupta, A., Dixit, A.K., Dixit, P. and Mahajan, C. Prevalence of gastrointestinal parasites in cattle and buffaloes in and around Jabalpur, Madhya Pradesh. J. vet. Parasitology, 26(2), 2012, 186-188.

[2] Agrawal M.C. Parasitology in India since independence, Ind. J. Anim. Sci, 68(8), 1998, 793-799.

[3] Chandra, D., Singh, K.P., Rathore, R., Raina, O.K. and Varghese, A. Acute Fasciolosis in cattle and buffaloes in Bareilly district, Ind. J. Vet. Pathol, 35(2), 2011, 133-135.

[4] Banerjee P.S., Yadav C.L., Ram, H. and Garg, R. An outbreak of acute Fasciolosis in buffaloes in Tarai region. XII NCVP held at Veterinary College Tirupati, 2001.

[5] Urquhart, G.M., Armour, J., Duncan, J.R., Dunn, A.M. and Lennings, F.W. Veterinary Parasitology, 2nd edition, Longman Group Ltd, London, UK, 1996, pp: 100-109.

[6] Singh, S.K.R. and Srivastava, H.D. Diagnosis and treatment of helminth infections. Division of Parasitology, Indian Vet. Res. Inst., Izatnagar, Uttar Pradesh, India, 1977.

[7] Luna, L. G. Mannual of histologic staining method of the Armed Forces Institute of Pathology. $3^{\text {rd }}$ Edn. McGraw Hill Book Co. New York, Toronto, London, Sydney, 1968.

[8] Meemon, K., Khawsuk, W., Sriburee, S., Meepool, A., Sethadavit, M., Sansri, V., Wanichanon, C. and Sobhon, P. Fasciola gigantica: Histology of the digestive tract and the expression of cathepsin L, J. Experimental Parasitol, 125, 2010, 371-379.

[9] Kuchai J. A., Chishti, M. Z., Ahmad, F. and Dar, S. A. On morphology of Fasciola gigantica recovered from Ruminants of a Cold Desert - Ladakh, DAV Int. J. Sci, 2(1), 2013.

[10] Soulsby E. J. L. Helminths, Arthropods and Protozoa of Domesticated Animals. 7 ed, Bailliere Tindall, London, 2005. 